\title{
REVIEW \\ Pluripotent stem cells in neuropsychiatric disorders
}

\author{
MA Soliman ${ }^{1,2,4}$, F Aboharb ${ }^{1,3,4}$, N Zeltner ${ }^{2}$ and L Studer ${ }^{1,2}$
}

Neuropsychiatric disorders place an enormous medical burden on patients across all social and economic ranks. The current understanding of the molecular and cellular causes of neuropsychiatric disease remains limited, which leads to a lack of targeted therapies. Human-induced pluripotent stem cell (iPSC) technology offers a novel platform for modeling the genetic contribution to mental disorders and yields access to patient-specific cells for drug discovery and personalized medicine. Here, we review recent progress in using iPSC technology to model and potentially treat neuropsychiatric disorders by focusing on the most prevalent conditions in psychiatry, including depression, anxiety disorders, bipolar disorder and schizophrenia.

Molecular Psychiatry (2017) 22, 1241-1249; doi:10.1038/mp.2017.40; published online 21 March 2017

\section{INTRODUCTION}

Global burden of psychiatric disorders

Neuropsychiatric illnesses greatly burden the health care system, economy and wellbeing of affected patients and their dependents worldwide. The magnitude of this problem is illustrated by several facts. First, when assessed in disability-adjusted life years (DALYs) -a measure of the number of years lost because of poor health, disability and early death-mental illness and substance use disorders accounted for a total of 173.1 million DALYs or roughly $7.1 \%$ of total disease burden worldwide (Figure $1 \mathrm{a}) .{ }^{1}$ In the United States, major depression ranked 5th and anxiety ranked 13th out of 291 medical conditions contributing to DALY burden. ${ }^{2}$ Globally, major depressive disorder (MDD) ranked 5th among the top 10 causes for disability in developed countries. ${ }^{1}$ Second, the global burden attributable to mental diseases has been steadily rising in recent years. Between 1990 and 2010, the burden of neuropsychiatric and substance use disorders has increased by nearly $22 \%$ (Figure $1 \mathrm{~b}$ ). ${ }^{3}$ Recently, Vigo et al. $^{4}$ compellingly argued that the global burden of mental illness is likely underestimated by more than one-third, suggesting that the effect of psychiatric disease may be even more dramatic than currently estimated. Finally, mental illness also leads to a significant economic impact estimated to be equivalent to the cost of cancer care. ${ }^{5}$ Serious mental illness was estimated to be associated with a loss of $\$ 193.2$ billion in personal earnings across the United States. ${ }^{6}$

Despite the fact that many epidemiologic studies on neuropsychiatric diseases are conducted in the developed world, mental health represents a major problem globally. Of the 188 countries examined in the Global Burden of Disease Study 2013, depression was in the top 10 causes of DALYs for 130 countries $(69 \%){ }^{1}$ These figures are worrisome given that outside of the western world, additional factors further complicate patient care. For example, psychiatrists and persons trained to treat mental illness are exceptionally scarce in many poor countries. ${ }^{7}$ It is estimated that $75 \%$ of mental health patients in low-income countries do not have access to care. ${ }^{8}$ Moreover, social and cultural factors lead to a stigma surrounding mental disorders, which deters patients from seeking appropriate treatment. ${ }^{9}$ Taken together, this grim picture highlights the tremendous need for an in-depth understanding of and effective treatments for mental disorders. It also raises the important question: Where does research on neuropsychiatric illness currently stand?

\section{UNDERSTANDING NEUROPSYCHIATRIC DISEASE}

Challenges in research

Despite the great progress made in recent decades, our knowledge of the pathophysiology of many common neuropsychiatric disorders remains limited. The lag experienced in this domain compared with other medical fields is not without cause; several unique obstacles exist in the study of mental diseases. First, mental disorders represent dysfunction in the least understood organ of the human body: the brain. Second, our limited understanding for the genetic basis of mental illness suggests great complexity. Studies on twins repeatedly show that the genetic makeup of affected neuropsychiatric patients contributes to their disease. ${ }^{10}$ For example, heritability for bipolar disorder (BPD) and schizophrenia (SCZ) is estimated to be between 80 and $90 \%{ }^{11,12}$ This degree of heritability is higher than that associated with breast cancer (30\%), ${ }^{13}$ type II diabetes $(50-70 \%)^{14}$ and hypertension $(40-60 \%){ }^{15}$ Moreover, genome-wide association studies show that psychiatric diseases are generally polygenic, with several genetic variants contributing a fraction of the overall risk and phenotype. ${ }^{16}$ Further complicating matters, many of these genetic variants exist in non-coding regions with unknown functions. ${ }^{16}$ Notable exceptions include Rett and Fragile $X$ Syndromes, which arise from defined monogenetic risk factors. ${ }^{17}$

Third, a paucity of model systems stifles the study of neuropsychiatric disorders. Despite the great utility of animal models in probing conserved neuronal molecular pathways and elucidating neuronal circuits, they fail to fully recapitulate any of the psychiatric disorders defined in the Diagnostic and Statistical Manual of Mental Disorders, Fifth Edition (DSM-5). The DSM-5defined diseases also likely represent an assortment of more

${ }^{1}$ Weill Cornell Medical College, Cornell University, New York, NY, USA; ${ }^{2}$ Developmental Biology and Center of Stem Cell Biology, Sloan-Kettering Cancer Center, New York, NY, USA

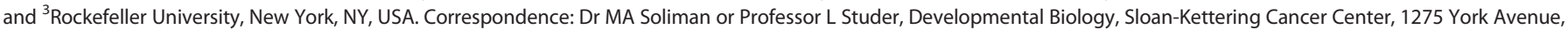
Box 256, New York, NY 10065, US.

E-mail: mos2028@med.cornell.edu or studerl@mskcc.org

${ }^{4}$ These authors contributed equally to this work.

Received 14 October 2016; revised 19 December 2016; accepted 9 January 2017; published online 21 March 2017 


\section{DALYs}

Disability adjusted Life Years, a metric for disease burden, represents the sum of Years Lived with Disability (YLDs) and Years lost due to early death (YLLs).
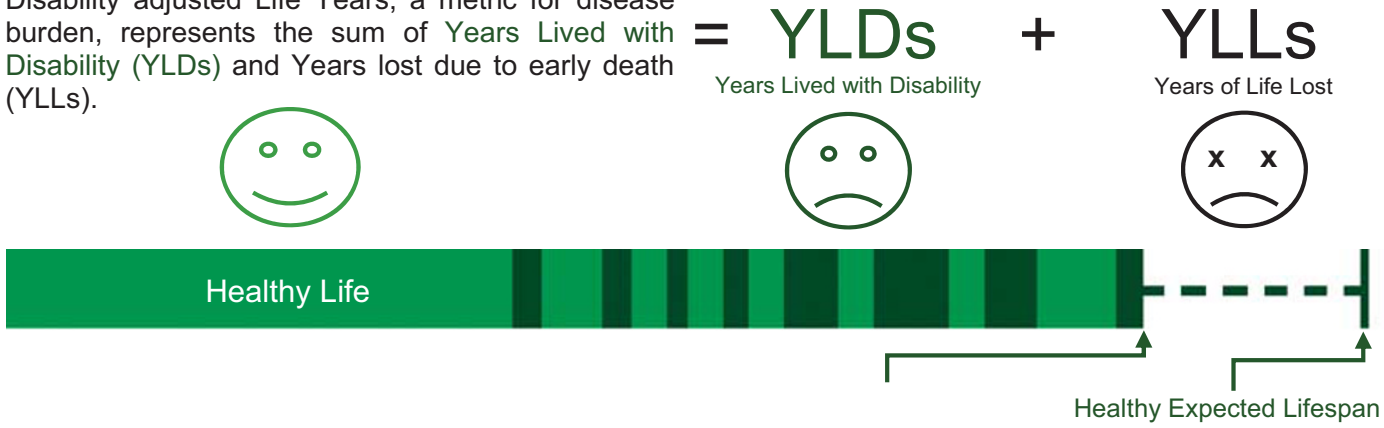

b

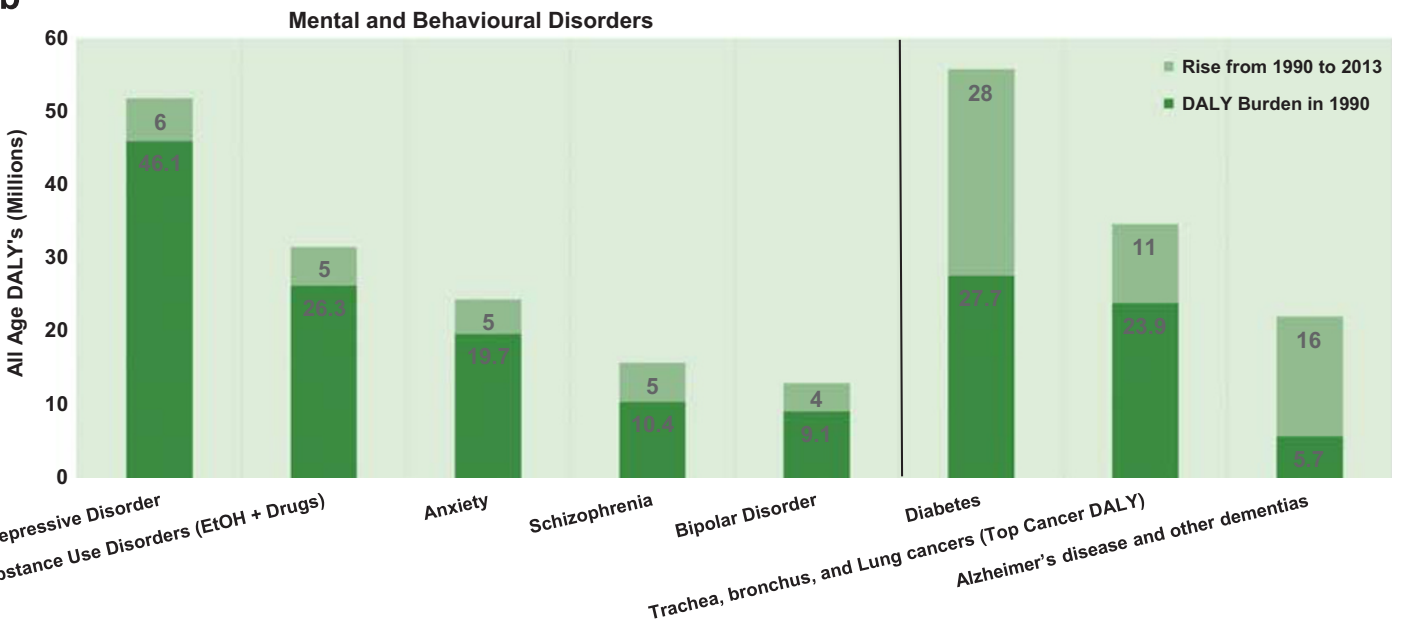

Adapted from a systematic analysis for the GBD 2010 and GBD 2013

Figure 1. (a) Graphic representation of disability-adjusted life years (DALYs), years lived with disability (YLDs) and years of life lost (YLLs). (b) Graph representing the DALY burden of leading neuropsychiatric disorders, as well as comparable non-neuropsychiatric diseases.

circuit-specific pathologies, each triggering a related set of symptoms. Therefore, it may not be feasible to capture a given neuropsychiatric disorder in a single model organism. The limited access to disease-relevant tissue and cell types in humans represents a major obstacle toward probing disease mechanisms. To gain greater insight at the molecular level, the scientific community uses patient biopsies, cell lines and post-mortem tissue. Each of these approaches remains suboptimal for studying neuropsychiatric diseases. Biopsies of brain tissue are highly invasive, ethically problematic to obtain and yield little material. Moreover, post-mitotic neurons cannot be expanded in vitro. Commonly used cell lines do not apply to the study of neuropsychatric diseases, and only a few immortalized brainderived cell lines exist. Furthermore, the few relevant cell lines fail to fully recapitulate disease etiology or patient genetics. Currently, the best method of accessing patient-specific brain tissues is postmortem sampling, which typically represents late stages of disease and offers little direct insight into the pathogenesis of disorders that often present early in life. In addition, these tissues rarely represent the natural course of disease progression because most patients receive some form of medical or psychological intervention after diagnosis. Layered on these confounding factors are the various comorbidities that accompany mental illness and variations in artifacts owing to different methods of fixation and storage of post-mortem tissues. Thus, advancing our understanding of neuropsychiatric disease will rely on technology that allows greater access to human neuronal cell types affected in mental illness and is capable of capturing patient genetic makeup. Such an advance would facilitate the study of neuropsychiatric disorders at a cellular and molecular level and the role of genetic variants in disease etiology. This will also provide a new platform for drug screening to identify new and improved therapies.

Induced pluripotent stem cells: development backward In 1998, Thomson et al. ${ }^{18}$ first established the technique of isolating human embryonic stem cells (hESCs) from blastocysts. When cultured, these cells can be maintained in an undifferentiated, pluripotent state indefinitely, enabling researchers to generate an unlimited number of cells. Furthermore, hESCs are pluripotent and thus can differentiate into any human tissue, including neurons and glia when guided through the appropriate developmental pathways. This is traditionally achieved through exposing hESCs to a combination of growth factors and modulators of specific signaling pathways. These protocols can generate progenitor cell types along the developmental spectrum and adult-like cell types of varying maturity. ${ }^{19}$ Hence, hESCs opened the door to investigating early human development and understanding molecular mechanisms driving cellular differentiation. However, the need to harvest these cells from human embryos generated considerable ethical controversy. This was resolved by the Nobel prize-winning discovery that adult somatic cells can be reprogrammed into cells with embryonic stem cell 


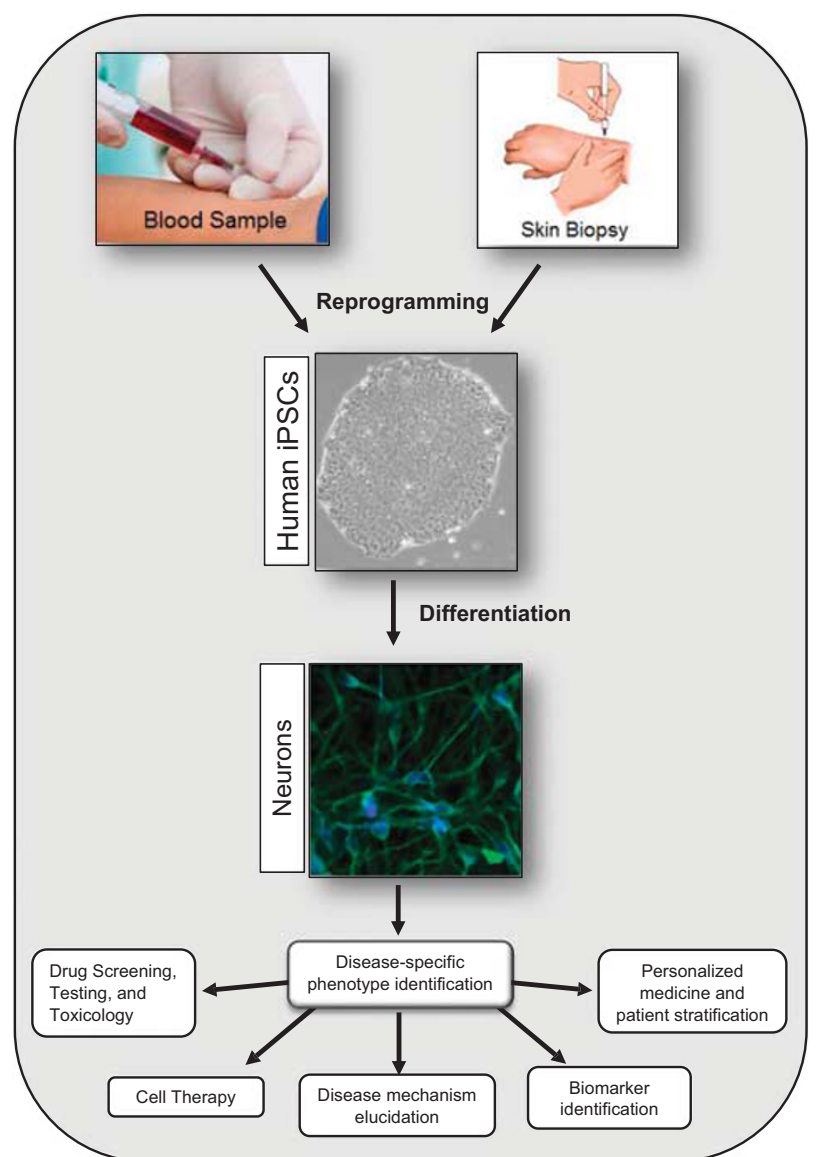

Figure 2. Schematic representation of induced pluripotent stem cell generation and application. A biopsy is taken from a patient (skin, blood or other tissues). Patient cells are reprogrammed into pluripotent stem cells and differentiated into the neuronal cell types of interest. Patient-derived neurons could be used for elucidating disease mechanism, high-throughput drug screening, drug testing and toxicity studies, biomarker identification and patient stratification. iPSC, human-induced pluripotent stem cell.

properties by the introduction of as few as four specific transcription factors. ${ }^{20}$ These cells were termed induced pluripotent stem cells (iPSCs).

A rapidly growing field of research has advanced iPSC generation and allowed for their derivation from patient fibroblasts, keratinocytes, $^{21}$ hair follicles, ${ }^{22}$ peripheral blood ${ }^{23}$ and likely most other cell types. The viral vectors originally used for delivering the reprogramming factors resulted in potentially deleterious genomic disruptions from viral integration. Integration-free viruses, plasmids, or small molecules are now routinely used to circumvent this issue. ${ }^{24}$ The generation of iPSCs remains a long and laborintensive process plagued by variability between iPSC lines. ${ }^{25} \mathrm{~A}$ recent approach addressed some of these issues through the use of a fully automated robotic cell reprogramming system, which may allow the generation of large cohorts of patient-specific iPSCs. ${ }^{26}$

One of the major advantages of the iPSC technology for modeling human diseases is that iPSCs contain the entire genetic background of the donor, making the technology particularly suitable to study diseases caused by defined genetic errors. One downside, however, is that epigenetic memory is erased during the reprogramming process. This poses a challenge to the study neuropsychiatric disorders which are greatly influenced by environmental factors known to leave their mark via epigenetic modifications. A sister technology to the traditional iPSC reprogramming method, called transdifferentiation (or direct reprogramming), circumvents the issue of epigenetic erasure by using transcription factors to directly induce a somatic cell to switch fates without passing through the pluripotent stem cell intermediate. ${ }^{27}$ This has been used to generate functional-induced neurons (iNs) directly from fibroblasts. ${ }^{27}$ Of note, transdifferentiated cells appear to retain much of their original epigenetic landscape ${ }^{28}$ (discussed in more detail in Limitations and Moving Forward in this review). Thus, generating iNs could be a valid alternative for the modeling of environmentally induced neuropsychiatric diseases, assuming that the epigenetic changes present in the somatic cells of the patient, such as in skin fibroblasts, are relevant in the context of modeling a neuropsychiatric disease.

To date, iPSC technology has proven largely successful in modeling and recapitulating a variety of diseases in vitro, ${ }^{29}$ developing high-throughput screening (HTS) for drugs, ${ }^{30,31}$ testing of new and existing drug toxicology ${ }^{32}$ and uncovering disease mechanisms (Figure 2). ${ }^{33}$ Combined with recent advances in genome editing technologies, iPSCs became an even more powerful tool. For example, the CRISPR/Cas9 genome editing tool has been used to establish causality of disease-causing mutations through their repair and introduction. Recently, progress has been made toward modeling genetically complex diseases, such as Parkinson's disease, through the combination of CRISPR/Cas9, genome-wide association studies and epigenetics with iPSCs to address the role of a non-coding variant. ${ }^{34}$ In addition, CRISPR/ Cas9 could be utilized to study coding variants expressed from endogenous loci and to investigate the function of single variants through isogenic controls. Hence, this technology holds promise for advancing precision medicine, patient stratification ${ }^{35}$ and cellbased therapies. ${ }^{36}$ Taken together, iPSC technology offers great potential to overcome many obstacles currently impeding progress toward understanding and treating mental illness.

\section{MODELING NEUROPSYCHIATRIC DISEASES USING IPSCs: THERAPEUTIC IMPLICATIONS}

Initially, researchers focused on modeling monogenetic neuropsychiatric disorders, including Rett and Fragile $X$ syndromes $^{37}$ (reviewed elsewhere ${ }^{38,39}$ ). However, recent reports highlight the power of using iPSC-derived neurons to model psychiatric disorders from patients with non-monogenic causes. ${ }^{40}$ iPSC technology has also been used to study the role of non-coding variants associated with mental diseases. ${ }^{41}$ Here, we primarily highlight efforts made over the past few years to model the molecular and physiological phenotypes observed in iPSC-derived neurons from patients with the most prevalent neuropsychiatric disorders, namely depression and anxiety disorders, BPD and SCZ (Figure 3).

\section{Depression and anxiety disorders}

MDD affects roughly 300 million people worldwide, which translates to approximately $4.5 \%$ of the global population. ${ }^{42}$ In 2010, it caused more DALY burden than diabetes. ${ }^{42}$ MDD diagnostic criteria include two or more weeks of decreased mood or markedly diminished interest or pleasure in most activities combined with one or more of the following criteria: severe change in appetite and sleeping habits, psychomotor agitation or retardation, excessive guilt, diminished concentration, or recurrent thoughts of death. First-line treatment currently includes selective serotonin reuptake inhibitors (SSRIs) and serotonin-norepinephrine reuptake inhibitors (SNRIs). Given the assumed mechanism of these medications, research has focused on finding genetic variants in the synthesis and signal conduction pathways of monoamines. Anxiety disorders follow closely behind MDD and affect about $4 \%$ of the global population. ${ }^{42}$ Anxiety disorders 


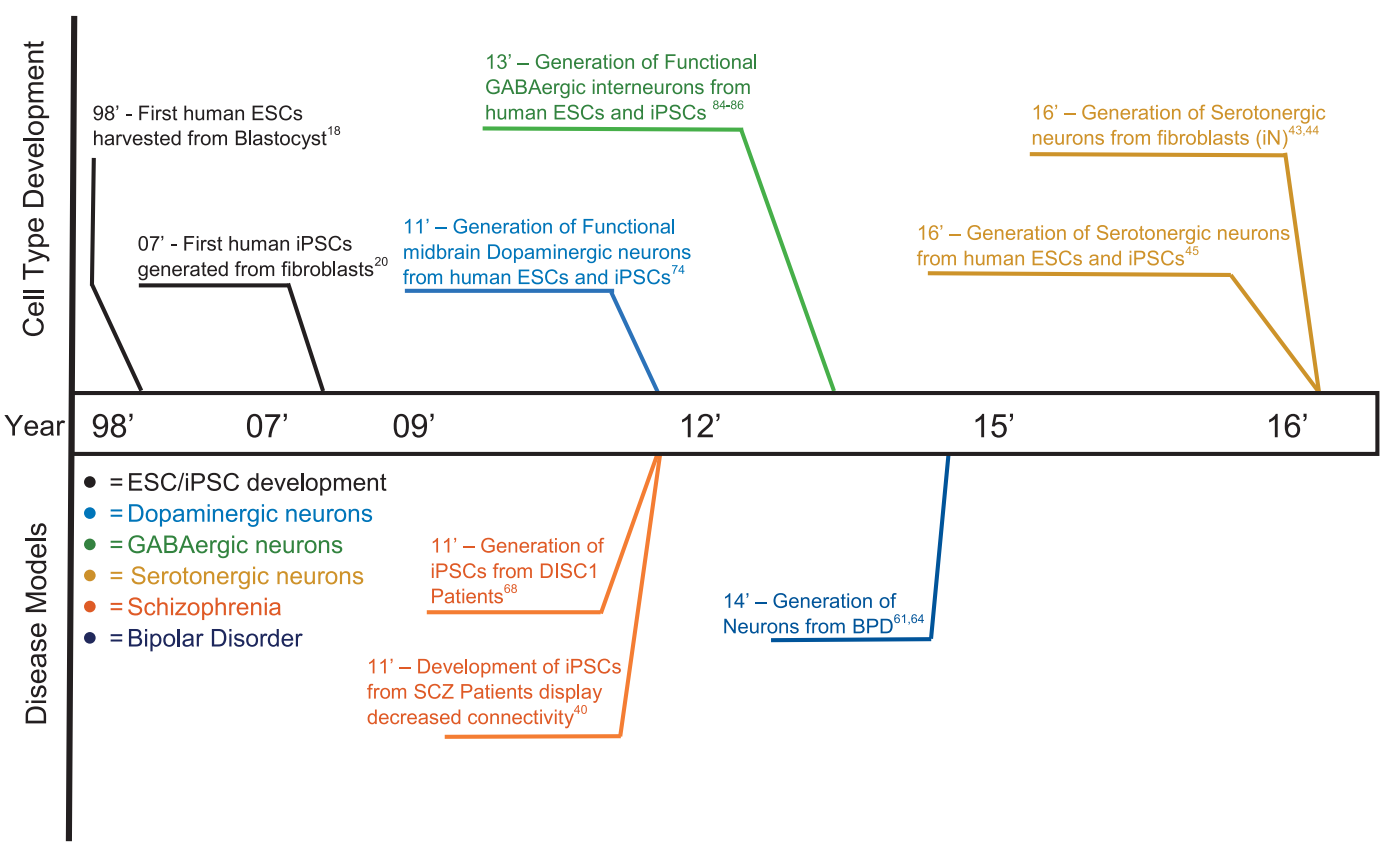

Figure 3. Timeline of iPSC technology development. Developments of neuropsychiatric disease models are represented on the lower side of the timeline panel, whereas developments in generating specific neuronal cell populations are represented in the upper part of the panel. BPD, bipolar disorder; iPSC, human-induced pluripotent stem cell; SCZ, schizophrenia.

include panic, generalized anxiety, obsessive compulsive, posttraumatic stress and phobic disorders. They are all characterized by the presence of a persistent and severe anxiety, sense of dread or foreboding thoughts. First-line treatment includes a combination of psychotherapy with pharmacological agents, such as SSRIs.

Up until recently, attempts to model neuropsychiatric diseases related to serotonergic transmission in vitro had been unsuccessful. In 2016, two groups independently developed a method for generating serotonergic neurons via transdifferentiation directly from human fibroblasts. ${ }^{43,44}$ Of note, Vadodaria and colleagues made use of citalopram, an SSRI, to show that these neurons could be potential tools for screening therapeutic compounds. In contrast, Lu et al. ${ }^{45}$ used hESCs and fibroblast-derived iPSCs to generate serotonergic neurons via temporal exposure of the cells to growth factors and modulators of signaling pathways. The group subsequently used the SSRI escitalopram to establish the utility of these neurons as screening tools for serotonin modulators. The development of reliable differentiation methods represents a leap forward in dissecting serotonin's role in depression. If these serotonergic neurons are made from patients, they can be used to screen for new therapeutics and elucidate the unknown mechanisms through which current drugs may function. ${ }^{46,47}$ This development may lead to the discovery of new drug targets and new insights into the molecular biology of depression.

Although serotonin modulators are currently first-line treatment for MDD and anxiety disorders, other neuronal populations are believed to have a role. For example, dysregulation of GABAergic neurons has also been implicated in depression and anxiety. ${ }^{48}$ Patients with MDD have reduced GABA receptors in the parahippocampal and lateral temporal lobes. ${ }^{49}$ Depressed patients showed a reduction in the number $(50 \%)$ and size $(18 \%)$ of GABAergic neurons in the dorsolateral prefrontal cortex and orbitofrontal cortex compared with control patients. ${ }^{50}$ Indeed, long-term treatment with different types of antidepressant therapies leads to enhanced GABAergic transmission through a GSK3 $\beta$-mediated mechanism. ${ }^{51,52}$ GABAergic cell therapy has already been applied to animal models ${ }^{53,54}$ and may have a role in the treatment of MDD (for more on GABAergic based disease modeling and therapy, refer to the SCZ section of this review).

In addition, deficiencies of brain-derived neurotrophic factor (BDNF) have a role in depression, anxiety and other neuropsychiatric illnesses. ${ }^{55,56}$ Indeed, the acute behavioral effects of SSRIs and tricyclic antidepressants seem to require BDNF signaling, ${ }^{57}$ suggesting that BDNF holds great potential as a therapeutic agent. ${ }^{58}$ Cell therapies focused on correcting BDNF deficiencies in mice have had some success. After a chronic stressor challenge, mice treated with human iPSC-derived neural progenitors overexpressing BDNF experienced greater neurogenesis than control mice. $^{59}$ Thus, it is conceivable that iPSC-derived cells with inducable BDNF expression may one day be used in a form of cell-based therapy for psychiatric patients.

Collectively, the development of differentiation protocols for serotonergic and GABAergic neuronal populations will pave the way for examining the role of these populations in the pathogenesis of depression and anxiety, and may eventually open the door for cell-based therapies in human. In vitro models could also be used to pre-select the most effective therapy for patients with MDD and anxiety disorders, as a step towards the application of precision medicine in psychiatry.

\section{Bipolar disorder}

BPD affects about $1 \%$ of the U.S. population. ${ }^{60}$ Patients with BPD present with episodes of major depression interspersed with bouts of mania or hypomania. First-line treatment includes mood stabilizers, such as lithium and valproic acid. Over the past 2 years, a few groups managed to generate iPSC-derived neurons from fibroblasts isolated from patients with BPD and healthy control patients. ${ }^{61-64}$ In one study, iPSC lines were derived from two brothers with BPD and their unaffected parents. ${ }^{62}$ Several genes were differentially expressed in BPD-derived neuronal precursor cells, most of which regulate neuronal differentiation, projection and calcium binding. Interestingly, neuronal precursor cells generated from BPD patients showed impaired neural differentiation and decreased proliferation, both of which were rescued by 
treatment with a selective inhibitor of the enzyme GSK3 $\beta$ (a known target of lithium therapy). ${ }^{62}$ Another group reprogrammed fibroblasts derived from patients with BPD, half of whom were responsive to lithium treatment, to iPSC-derived hippocampal dentate gyrus granule cell-like neurons, which are reportedly affected in BPD. ${ }^{63}$ Of note, BPD-derived neurons showed altered expression of mitochondrial, calcium-signaling and neuronal excitability genes. In addition, when compared with controls, BPD-derived neurons exhibited a hyperexcitability phenotype as evidenced by higher frequency of spontaneous action potentials. Remarkably, a 1-week treatment with lithium partially normalized changes in mitochondrial gene expression and hyperexcitability phenotype only in neurons derived from patients with BPD who were responsive to lithium. ${ }^{63}$ These recent findings suggest a role for mitochondrial signaling in BPD and shed light on potential molecular mechanisms that could explain the differences in patient responsiveness to lithium treatment. ${ }^{65}$

Seeing a specific phenotype in disease-relevant neurons in vitro represents an exciting first step in the development of an iPSCbased disease model. However, it is often challenging to determine the significance of an in vitro phenotype for a given disease. Such phenotypes are difficult to evaluate given the lack of primary tissue from patients for further confirmation and the overall lack of understanding of disease-initiating events in neuropsychiatric diseases. One desirable endpoint is to use such disease-related phenotypes as the starting point for HTS, which allows for testing hundreds of compounds simultaneously. One group has developed a HTS for testing various compounds on human iPSC-derived neurons for modulators of the Wnt/GSK3 $\beta$ signaling system, ${ }^{66}$ a system further validated through the use of lithium.

\section{Schizophrenia}

SCZ affects more than 21 million patients worldwide. ${ }^{67}$ Diagnosis is made when a patient presents with at least 6 months of perturbed language, perception, thinking, social activity, affect and volition. First-line treatments include atypical antipsychotics, such as olanzapine and risperidone. SCZ was among the first neuropsychiatric disorders modeled with patient iPSC-derived neurons. ${ }^{40,68}$ In one of those studies, SCZ-iPSC-derived neurons showed decreased connectivity, synapses, spine density and expression of glutamate receptors when co-cultured with human astrocytes. ${ }^{40}$ Interestingly, treatment with the dopaminergic antagonist loxapine, but not clozapine, olanzapine, risperidone or thioridazine, during the last 3 weeks of neuronal differentiation increased neuronal connectivity in iPSC-derived neurons from all patients. The inability of the structurally similar antipsychotic clozapine to rescue phenotypes observed in defective neurons raises the question about the exact mechanism by which loxapine acts in this system. Another group generated iPSC lines from family members carrying mutant DISC1 and demonstrated synaptic defects in those iPSC-derived neurons. ${ }^{33}$ Genes related to synaptic transmission and development were dysregulated, about 90 of which had been previously linked to mental disorders, including depression, BPD and SCZ. Intriguingly, using gene editing techniques, the group established a causal link between the DISC1 mutation and the observed defects. ${ }^{33}$

One of the mainstream theories behind the pathogenesis of SCZ is dopamine dysregulation. Studies supporting this theory show aberrant dopamine transmission within multiple brain regions, ${ }^{69}$ including the amygdala, ${ }^{70}$ prefrontal $\operatorname{cortex}^{71,72}$ and hippocampus. ${ }^{73}$ Our group has established an efficient differentiation protocol for generating midbrain dopaminergic neurons, which showed long-term survival when engrafted in mouse, rat and monkey models. ${ }^{74}$ Numerous groups have used and adapted this protocol for the generation of dopaminergic neurons from patients with SCZ. ${ }^{75,76}$ Dopaminergic neurons differentiated from
iPSCs derived from patients with SCZ had a reduced neurite count and dopamine release and showed delayed maturation. ${ }^{76}$ Interestingly, these defective neurons exhibited perturbations in mitochondrial network structure and connectivity. This suggests a potential mitochondrial defect having a key role in the pathogenesis of SCZ, much like that reported in BPD. ${ }^{63}$ Reports indicating that iPSCs from some patients with SCZ show poor differentiation into dopaminergic neurons, ${ }^{75}$ suggesting a need to improve current protocols before those neurons can serve as a robust platform to study the factors contributing to the dysregulation of dopamine in SCZ. Such further improvements may also facilitate the development of cell-based screens for the identification of novel candidate therapeutic compounds or to guide future treatment choices in individual patients.

Studies have tied the hyperfunctioning of the dopaminergic system to hyperexcitability in the hippocampus, ${ }^{77,78}$ one of the potential drivers of which is the reduced number of GABAergic interneurons providing tonic inhibitory control. ${ }^{79,80}$ Human studies also suggest a major role for GABAergic dysfunction in SCZ. Post-mortem studies of SCZ brains reveals a $40 \%$ reduction in GABAergic synapses, ${ }^{81}$ which is a deficiency that may originate during development. ${ }^{82}$ Indeed, grafting GABAergic neurons into the ventral hippocampus in the rodent model of SCZ restored normal hippocampal functioning, corrected downstream dopaminergic dysregulation and rescued behavioral deficits. ${ }^{54,83}$

To better probe the nature of GABAergic interneurons and their potential role in disease pathogenesis, several groups have developed differentiation protocols to produce these neurons using hESCs or iPSCs. ${ }^{84-86}$ Interestingly, these studies provide evidence that human GABAergic interneurons have a lengthy maturation period, requiring as long as 7 months to reach mature phenotypes. The ability to generate interneurons opens the door to potential GABAergic cell-based therapies in the treatment of $\mathrm{SCZ}^{87}$ and other diseases associated with GABAergic dysfunction, such as depression, ${ }^{50}$ epilepsy ${ }^{53}$ and neuropathic pain. ${ }^{88}$

\section{LIMITATIONS AND MOVING FORWARD}

Human iPSC models provide an invaluable tool to dissect the molecular and pathophysiological defects underlying neuropsychiatric disorders and offer a powerful platform for drug screening in disease-relevant cells. Although this system addresses many challenges associated with studying mental illness, important limitations remain. ${ }^{89}$ First, epigenetic erasure: the current dogma in the field states that upon reprogramming, not only is the cellular lineage identity reset, but the epigenetic landscape of the cell is erased. ${ }^{90}$ This gives the cell a relatively clean slate on which to form the modifications necessary to differentiate into any cell type of the body, much like the germline reprogramming that facilitates totipotency in the mammalian zygote. ${ }^{91}$ However, this is problematic for the study of neuropsychiatric diseases, such as depression or anxiety, which are greatly influenced by environmental factors known to modify epigenetics. There is evidence that some epigenetic memory is retained through the reprogramming process, which is supported by the tendency of iPSCs derived from blood cells to preferentially differentiate toward mesoderm lineages (that is, their lineage of origin). ${ }^{28}$ However, such epigenetic memory may not persist long-term in iPSCs as repeated passaging at the pluripotent state is correlated with a loss of the lineage-specific differentiation bias. ${ }^{92}$ Furthermore, there is a possibility that some retained epigenetic memory represents incomplete reprogramming of the iPSCs. Transdifferentiated cells (iNs) appear to retain much of their original epigenetic landscape. ${ }^{93}$ Thus, generating iNs could be a valid alternative for the modeling of environmentally induced neuropsychiatric diseases. Although induced neuron technology may better preserve the epigenetic landscape of the patient donor cell, epigenetic modifications vary across different cell types and 
Table 1. Selected human iPSC-based reports modeling SCZ and BPD

\begin{tabular}{|c|c|c|c|}
\hline Disease & Authors, year, journal & Neuronal cell & Main finding \\
\hline \multirow{4}{*}{ SCZ } & $\begin{array}{l}\text { Pedrosa et al., } 2011 \text {, } \\
J \text { Neurogenetics }\end{array}$ & Glutamatergic neurons & $\begin{array}{l}\text { First study to model the SCZ risk factor } 22 \mathrm{q} 11 \text { using patient-derived } \\
\text { iPSCs. }\end{array}$ \\
\hline & $\begin{array}{l}\text { Hook et al., 2014, } \\
\text { Stem Cell Reports }\end{array}$ & NPCs and neurons & $\begin{array}{l}\text { Increased secretion of catecholamines, higher numbers of } \mathrm{TH}^{+} \\
\text {neurons in patient-derived neurons }\end{array}$ \\
\hline & $\begin{array}{l}\text { Siegert et al., } 2015 \\
\text { Nat Neuroscience }\end{array}$ & $\begin{array}{l}\text { Direct conversion of fibroblasts to } \\
\text { neurons }\end{array}$ & $\begin{array}{l}\text { Increasing miR-137 expression caused downregulation of } \\
\text { presynaptic target genes, impaired vesicle release, impaired synaptic } \\
\text { plasticity in hippocampus. These phenotypes were rescued by } \\
\text { sequestering miR-137 }\end{array}$ \\
\hline & $\begin{array}{l}\text { Srikanth et al., 2015, } \\
\text { Cell Rep }\end{array}$ & NPCs and neurons & $\begin{array}{l}\text { Increased level of canonical Wnt signaling, and altered expression of } \\
\text { neuronal fate markers such as Foxg1 and Tbr2 in NPCs derived from } \\
\text { DISC1-mutated cells. Gene expression changes are rescued by } \\
\text { antagonizing Wnt signaling in a critical developmental window }\end{array}$ \\
\hline \multirow{4}{*}{ BPD } & $\begin{array}{l}\text { Wang et al., 2014, Transl } \\
\text { Psychiatry }\end{array}$ & Neurons (transdifferentiation) & $\begin{array}{l}\text { Cell adhesion was associated with clinical response to lithium } \\
\text { treatment }\end{array}$ \\
\hline & $\begin{array}{l}\text { Bavamian et al., 2015, } \\
\text { Mol Psychiatry }\end{array}$ & NPCs and neurons & $\begin{array}{l}\text { miR-34a levels are increased in BPD patient-derived neuronal } \\
\text { cultures. Reducing endogenous miR-34a expression enhances } \\
\text { dendritic elaboration. }\end{array}$ \\
\hline & $\begin{array}{l}\text { Madison et al., 2015, } \\
\text { Mol Psychiatry }{ }^{2}\end{array}$ & NPCs & $\begin{array}{l}\text { Abnormalities in early steps in NPC formation, WNT/GSK3 signaling } \\
\text { and ion channels expression in the BPD patient-derived NPCs and } \\
\text { neurons. Rescue of proliferation defects in BPD patient NPCs with } \\
\text { GSK3 inhibition }\end{array}$ \\
\hline & $\begin{array}{l}\text { Mertens et al., 2015, } \\
\text { Nature }^{63}\end{array}$ & $\begin{array}{l}\text { Hippocampal dentate gyrus-like } \\
\text { neurons }\end{array}$ & $\begin{array}{l}\text { Changes in the expression of genes linked to mitochondrial function } \\
\text { and neuronal excitability; reduced mitochondrial size and enhanced } \\
\text { function in BPD neurons. Lithium reduced the hyperexcitability of LR } \\
\text { neurons and partly normalized their mitochondrial function }\end{array}$ \\
\hline
\end{tabular}

therefore changes in skin fibroblasts may not capture important neuron-specific disease-related epigenetic differences. ${ }^{94}$ The emerging field of transgenerational epigenetic inheritance provides evidence that environmental influences, including nutrition or stress, can modify epigenetic marks inherited across the germline. ${ }^{95,96}$ Thus, such marks may persist through the reprogramming process and be of use in the study of mental illness with environmental contributions.

Second, developmental state: neurons differentiated from iPSCs most closely resemble cells of the fetal brain, a problem for modeling diseases that emerge later in life. ${ }^{97}$ This topic is the subject of active research aiming at developing techniques to mimic cellular maturation and aging. ${ }^{98}$ Third, current protocols for generating iPSCs vary in efficiency and produce heterogeneous populations. ${ }^{25}$ This could be due to the fact that iPSCs accumulate mutations in culture over time. ${ }^{99}$ Although transdifferentiation techniques skip potentially crucial phases of neuronal development, these techniques offer a potential solution for this problem. ${ }^{100}$ Fourth, current techniques for differentiating iPSCs yield a heterogeneous population of neuronal subtypes, which may have varying roles in disease pathogenesis. ${ }^{101}$ Future protocols differentiating iPSC into more precisely defined neural subtypes may reveal phenotypes that are hidden using current protocols. Fifth, the expensive and time-consuming nature of generating iPSCs and differentiating them into neurons often leads to small sample sizes for most reported studies. Currently, scaling up the experiments to include more subjects remains a major obstacle. However, new techniques are being developed to reduce the time and costs required to generate patient-specific neurons. ${ }^{101}$ Sixth, the pathogenesis of many neuropsychiatric diseases most likely lies at the level of neuronal circuits, making them difficult to study using iPSC technology. Co-culture systems $^{102}$ and 3 -dimensional organoids ${ }^{103-105}$ provide systems potentially capable of recapitulating circuit level interactions, to address this challenge. Importantly, iPSC-derived neurons have also been grafted into animal models to observe their circuit level interactions in vivo. ${ }^{74,106-108}$

\section{CONCLUSIONS}

Neuropsychiatric disorders affect a large proportion of the global population, and continues to affect more people every year. There is a tremendous need to identify pathophysiology of these disorders and find novel, targeted treatments. Major limitations in neuropsychiatric research include the lack of access to diseasespecific cell types. iPSC technology offers new opportunities to model disease-relevant neural cells from patients. Over the past 5 years, a handful of groups have applied this technology toward studying mental disorders, including SCZ and BPD (Table 1). Remarkably, these groups have developed differentiation protocols capable of generating specific cell populations, such as GABAergic, serotonergic and dopaminergic neurons. Despite the exciting progress made in recent years, this represents only a fraction of the potential iPSC technology holds for unlocking 
insights into the cause of mental illness. Although our knowledge of the causes behind mental illness has lagged, iPSC technology will push boundaries in our ability to understand, diagnose and treat neuropsychiatric disorders.

\section{Search strategy and selection criteria}

Data sources were identified through searches in PubMed. Search terms were as follows: (pluripotent OR transdifferentiation) AND (psychiatr* OR schizophrenia OR bipolar OR depressi* OR Anxiety). This yielded 374 articles as of June 2016. Publications in English were used.

\section{CONFLICT OF INTEREST}

The authors declare no conflict of interest.

\section{ACKNOWLEDGMENTS}

We thank Brandon Valentine for careful reading of the manuscript. Issa Bagayogo for insight into global mental health. NZ was funded by the Swiss National Science Foundation Mobility fellowship PA00PA3-142203/1 and P300P3-154667. MAS is funded by scholarships from Cornell University Medical College, New York County Society of Psychiatry and Thermo-Fischer Scientific. FA was supported by a Medical Scientist Training Program grant from the National Institute of General Medical Sciences of the National Institutes of Health under award number: T32GM007739 to the Weill Cornell/Rockefeller/Sloan-Kettering Tri-Institutional MD-PhD Program. LS is supported by grants from the National Institutes of Health (NINDS: R01NS072381, R21 NS084334; NCl: P30 CA008748), the Tri-institutional stem cell initiative (Starr Foundation) and NYSTEM (C026446 and C026447).

\section{DISCLAIMER}

The content of this study is solely the responsibility of the authors and does not necessarily represent the official views of the National Institutes of Health.

\section{AUTHOR CONTRIBUTIONS}

MAS and FA wrote and edited the manuscript, and made the figures. NZ wrote the introduction and limitation sections. LS critically read and edited the manuscript.

\section{REFERENCES}

1 Murray CJ, Barber RM, Foreman KJ, Abbasoglu Ozgoren A, GBD 2013 DALYs and HALE Collaborators et al. Global, regional, and national disability-adjusted life years (DALYs) for 306 diseases and injuries and healthy life expectancy (HALE) for 188 countries, 1990-2013: quantifying the epidemiological transition. Lancet 2015; 386: 2145-2191.

2 Murray CJ, Atkinson C, Bhalla K, Birbeck G, Burstein R, Chou D et al. The state of US health, 1990-2010: burden of diseases, injuries, and risk factors. JAMA 2013; 310: 591-608.

3 Whiteford HA, Degenhardt L, Rehm J, Baxter AJ, Ferrari AJ, Erskine HE et al. Global burden of disease attributable to mental and substance use disorders: findings from the Global Burden of Disease Study 2010. Lancet 2013; 382: 1575-1586.

4 Vigo D, Thornicroft G, Atun R. Estimating the true global burden of mental illness. Lancet Psychiatry 2016; 3: 171-178.

5 Soni A. The Five Most Costly Conditions, 1996 and 2006: Estimates for the US Civilian Noninstitutionalized Population. Statistical Brief\# 248. Agency for Healthcare Research and Quality: Rockville, MD, USA, 2009.

6 Kessler RC, Heeringa S, Lakoma MD, Petukhova M, Rupp AE, Schoenbaum M et al. Individual and societal effects of mental disorders on earnings in the United States: results from the national comorbidity survey replication. Am J Psychiatry 2008; 165: 703-711.

7 Psychiatrists and nurses (per 100000 population) [Internet]. WHO. World Health Organization; [cited 16 February 2017]. Available from: http://www.who.int/gho/ mental_health/human_resources/psychiatrists_nurses/en/.

8 WHO Mental Health Gap Action Programme (mhGAP) [Internet]. WHO. World Health Organization; [cited 16 February 2017]. Available from: http://www.who. int/mental_health/mhgap/en/.
9 Lund C, Tomlinson M, De Silva M, Fekadu A, Shidhaye R, Jordans M et al. PRIME: a programme to reduce the treatment gap for mental disorders in five low-and middle-income countries. PLoS Med 2012; 9: e1001359.

10 Plomin R, Owen MJ, McGuffin P. The genetic basis of complex human behaviors. Science 1994; 264: 1733-1739.

11 McGuffin P, Rijsdijk F, Andrew M, Sham P, Katz R, Cardno A. The heritability of bipolar affective disorder and the genetic relationship to unipolar depression. Arch Gen Psychiatry 2003; 60: 497-502.

12 Sullivan PF, Kendler KS, Neale MC. Schizophrenia as a complex trait: evidence from a meta-analysis of twin studies. Arch Gen Psychiatry 2003; 60: 1187-1192.

13 Locatelli I, Lichtenstein P, Yashin Al. The heritability of breast cancer: a Bayesian correlated frailty model applied to Swedish twins data. Twin Res 2004; 7: 182-191.

14 Stumvoll M, Goldstein BJ, van Haeften TW. Type 2 diabetes: principles of pathogenesis and therapy. Lancet 2005; 365: 1333-1346.

15 Hunt SC, Hasstedt SJ, Kuida H, Stults BM, Hopkins PN, Williams RR. Genetic heritability and common environmental components of resting and stressed blood pressures, lipids, and body mass index in Utah pedigrees and twins. Am J Epidemiol 1989; 129: 625-638.

16 Gratten J, Wray NR, Keller MC, Visscher PM. Large-scale genomics unveils the genetic architecture of psychiatric disorders. Nat Neurosci 2014; 17: 782-790.

17 Lombardi LM, Baker SA, Zoghbi HY. MECP2 disorders: from the clinic to mice and back. J Clin Invest 2015; 125: 2914-2923.

18 Thomson JA, Itskovitz-Eldor J, Shapiro SS, Waknitz MA, Swiergiel JJ, Marshall VS et al. Embryonic stem cell lines derived from human blastocysts. Science 1998; 282: 1145-1147.

19 Murry CE, Keller G. Differentiation of embryonic stem cells to clinically relevant populations: lessons from embryonic development. Cell 2008; 132: 661-680.

20 Takahashi K, Tanabe K, Ohnuki M, Narita M, Ichisaka T, Tomoda K et al. Induction of pluripotent stem cells from adult human fibroblasts by defined factors. Cell 2007; 131: 861-872.

21 Aasen T, Raya A, Barrero MJ, Garreta E, Consiglio A, Gonzalez F et al. Efficient and rapid generation of induced pluripotent stem cells from human keratinocytes. Nat Biotechnol 2008; 26: 1276-1284.

22 Petit I, Kesner NS, Karry R, Robicsek O, Aberdam E, Muller FJ et al. Induced pluripotent stem cells from hair follicles as a cellular model for neurodevelopmental disorders. Stem Cell Res 2012; 8: 134-140.

23 Staerk J, Dawlaty MM, Gao Q, Maetzel D, Hanna J, Sommer CA et al. Reprogramming of human peripheral blood cells to induced pluripotent stem cells. Cell Stem Cell 2010; 7: 20-24.

24 Schlaeger TM, Daheron L, Brickler TR, Entwisle S, Chan K, Cianci A et al. A comparison of non-integrating reprogramming methods. Nat Biotechnol 2015; 33: 58-63.

25 Vitale AM, Matigian NA, Ravishankar S, Bellette B, Wood SA, Wolvetang EJ et al. Variability in the generation of induced pluripotent stem cells: importance for disease modeling. Stem Cells Transl Med 2012; 1: 641-650.

26 Paull D, Sevilla A, Zhou H, Hahn AK, Kim H, Napolitano C et al. Automated, highthroughput derivation, characterization and differentiation of induced pluripotent stem cells. Nat Methods 2015; 12: 885-892.

27 Vierbuchen T, Ostermeier A, Pang ZP, Kokubu Y, Sudhof TC, Wernig M. Direct conversion of fibroblasts to functional neurons by defined factors. Nature 2010; 463: 1035-1041.

28 Kim K, Doi A, Wen B, Ng K, Zhao R, Cahan P et al. Epigenetic memory in induced pluripotent stem cells. Nature 2010; 467: 285-290.

29 Avior Y, Sagi I, Benvenisty N. Pluripotent stem cells in disease modelling and drug discovery. Nat Rev Mol Cell Biol 2016; 17: 170-182.

30 Lee G, Ramirez CN, Kim H, Zeltner N, Liu B, Radu C et al. Large-scale screening using familial dysautonomia induced pluripotent stem cells identifies compounds that rescue IKBKAP expression. Nat Biotechnol 2012; 30: 1244-1248.

31 Wainger BJ, Kiskinis E, Mellin C, Wiskow O, Han SS, Sandoe J et al. Intrinsic membrane hyperexcitability of amyotrophic lateral sclerosis patient-derived motor neurons. Cell Rep 2014; 7: 1-11.

32 Medine CN, Lucendo-Villarin B, Storck C, Wang F, Szkolnicka D, Khan F et al. Developing high-fidelity hepatotoxicity models from pluripotent stem cells. Stem Cells Transl Med 2013; 2: 505-509.

33 Wen Z, Nguyen HN, Guo Z, Lalli MA, Wang X, Su Y et al. Synaptic dysregulation in a human iPS cell model of mental disorders. Nature 2014; 515: 414-418.

34 Soldner F, Stelzer Y, Shivalila CS, Abraham BJ, Latourelle JC, Barrasa MI et al. Parkinson-associated risk variant in distal enhancer of alpha-synuclein modulates target gene expression. Nature 2016; 533: 95-99.

35 Garbes L, Heesen L, Holker I, Bauer T, Schreml J, Zimmermann K et al. VPA response in SMA is suppressed by the fatty acid translocase CD36. Hum Mol Genet 2013; 22: 398-407.

36 Tabar V, Studer L. Pluripotent stem cells in regenerative medicine: challenges and recent progress. Nat Rev Genet 2014; 15: 82-92. 
37 Marchetto MC, Carromeu C, Acab A, Yu D, Yeo GW, Mu Y et al. A model for neural development and treatment of Rett syndrome using human induced pluripotent stem cells. Cell 2010; 143: 527-539.

38 Cundiff PE, Anderson SA. Impact of induced pluripotent stem cells on the study of central nervous system disease. Curr Opin Genet Dev 2011; 21: 354-361.

39 Haggarty SJ, Silva MC, Cross A, Brandon NJ, Perlis RH. Advancing drug discovery for neuropsychiatric disorders using patient-specific stem cell models. Mol Cell Neurosci 2016; 73: 104-115.

40 Brennand KJ, Simone A, Jou J, Gelboin-Burkhart C, Tran N, Sangar S et al. Modelling schizophrenia using human induced pluripotent stem cells. Nature 2011; 473: 221-225.

41 Roussos P, Mitchell AC, Voloudakis G, Fullard JF, Pothula VM, Tsang J et al. A role for noncoding variation in schizophrenia. Cell Rep 2014; 9: 1417-1429.

42 Vos T, Flaxman AD, Naghavi M, Lozano R, Michaud C, Ezzati M et al. Years lived with disability (YLDs) for 1160 sequelae of 289 diseases and injuries 1990-2010: a systematic analysis for the Global Burden of Disease Study 2010. Lancet 2012; 380: 2163-2196.

43 Xu Z, Jiang H, Zhong P, Yan Z, Chen S, Feng J. Direct conversion of human fibroblasts to induced serotonergic neurons. Mol Psychiatry 2016; 21: 62-70.

44 Vadodaria KC, Mertens J, Paquola A, Bardy C, Li X, Jappelli R et al. Generation of functional human serotonergic neurons from fibroblasts. Mol Psychiatry 2016; 21: 49-61.

45 Lu J, Zhong X, Liu H, Hao L, Huang CT, Sherafat MA et al. Generation of serotonin neurons from human pluripotent stem cells. Nat Biotechnol 2016; 34: 89-94.

46 Diaz SL, Doly S, Narboux-Neme N, Fernandez S, Mazot P, Banas SM et al. 5-HT(2B) receptors are required for serotonin-selective antidepressant actions. Mol Psychiatry 2012; 17: 154-163.

47 Richardson-Jones JW, Craige CP, Guiard BP, Stephen A, Metzger KL, Kung HF et al. 5-HT1A autoreceptor levels determine vulnerability to stress and response to antidepressants. Neuron 2010; 65: 40-52.

48 Mohler $\mathrm{H}$. The GABA system in anxiety and depression and its therapeutic potential. Neuropharmacology 2012; 62: 42-53.

49 Klumpers UM, Veltman DJ, Drent ML, Boellaard R, Comans EF, Meynen G et al. Reduced parahippocampal and lateral temporal GABAA-[11C]flumazenil binding in major depression: preliminary results. Eur J Nucl Med Mol Imaging 2010; 37: 565-574.

50 Rajkowska G, O'Dwyer G, Teleki Z, Stockmeier CA, Miguel-Hidalgo JJ. GABAergic neurons immunoreactive for calcium binding proteins are reduced in the prefrontal cortex in major depression. Neuropsychopharmacology 2007; 32: 471-482.

51 Okamoto H, Voleti B, Banasr M, Sarhan M, Duric V, Girgenti MJ et al. Wnt2 expression and signaling is increased by different classes of antidepressant treatments. Biol Psychiatry 2010; 68: 521-527.

52 Tyagarajan SK, Ghosh H, Yevenes GE, Nikonenko I, Ebeling C, Schwerdel C et al. Regulation of GABAergic synapse formation and plasticity by GSK3betadependent phosphorylation of gephyrin. Proc Natl Acad Sci USA 2011; 108: 379-384.

53 Cunningham M, Cho JH, Leung A, Savvidis G, Ahn S, Moon M et al. hPSC-derived maturing GABAergic interneurons ameliorate seizures and abnormal behavior in epileptic mice. Cell Stem Cell 2014; 15: 559-573.

54 Perez SM, Lodge DJ. Hippocampal interneuron transplants reverse aberrant dopamine system function and behavior in a rodent model of schizophrenia. Mol Psychiatry 2013; 18: 1193-1198.

55 Autry AE, Monteggia LM. Brain-derived neurotrophic factor and neuropsychiatric disorders. Pharmacol Rev 2012; 64: 238-258.

56 Vithlani M, Hines RM, Zhong P, Terunuma M, Hines DJ, Revilla-Sanchez R et al. The ability of BDNF to modify neurogenesis and depressive-like behaviors is dependent upon phosphorylation of tyrosine residues 365/367 in the GABA(A)receptor gamma2 subunit. J Neurosci 2013; 33: 15567-15577.

57 Saarelainen T, Hendolin P, Lucas G, Koponen E, Sairanen M, MacDonald E et al. Activation of the TrkB neurotrophin receptor is induced by antidepressant drugs and is required for antidepressant-induced behavioral effects. J Neurosci 2003; 23: 349-357.

58 Nagahara AH, Tuszynski MH. Potential therapeutic uses of BDNF in neurological and psychiatric disorders. Nat Rev Drug Discov 2011; 10: 209-219.

59 Liu G, Rustom N, Litteljohn D, Bobyn J, Rudyk C, Anisman H et al. Use of induced pluripotent stem cell derived neurons engineered to express BDNF for modulation of stressor related pathology. Front Cell Neurosci 2014; 8: 316.

60 Judd LL, Akiskal HS. The prevalence and disability of bipolar spectrum disorders in the US population: re-analysis of the ECA database taking into account subthreshold cases. J Affect Disord 2003; 73: 123-131.

61 Chen HM, DeLong CJ, Bame M, Rajapakse I, Herron TJ, McInnis MG et al. Transcripts involved in calcium signaling and telencephalic neuronal fate are altered in induced pluripotent stem cells from bipolar disorder patients. Transl Psychiatry 2014; 4: e375.
62 Madison JM, Zhou F, Nigam A, Hussain A, Barker DD, Nehme R et al. Characterization of bipolar disorder patient-specific induced pluripotent stem cells from a family reveals neurodevelopmental and mRNA expression abnormalities. Mol Psychiatry 2015; 20: 703-717.

63 Mertens J, Wang QW, Kim Y, Yu DX, Pham S, Yang B et al. Differential responses to lithium in hyperexcitable neurons from patients with bipolar disorder. Nature 2015; 527: 95-99.

64 Wang JL, Shamah SM, Sun AX, Waldman ID, Haggarty SJ, Perlis RH. Label-free, live optical imaging of reprogrammed bipolar disorder patient-derived cells reveals a functional correlate of lithium responsiveness. Transl Psychiatry 2014; 4: e428.

65 Harrison PJ, Cader MZ, Geddes JR. Reprogramming psychiatry: stem cells and bipolar disorder. Lancet 2016; 387: 823-825.

66 Zhao WN, Cheng C, Theriault KM, Sheridan SD, Tsai LH, Haggarty SJ. A high-throughput screen for Wnt/beta-catenin signaling pathway modulators in human iPSC-derived neural progenitors. J Biomol Screen 2012; 17: 1252-1263.

67 van Os J, Kapur S. Schizophrenia. Lancet 2009; 374: 635-645.

68 Chiang CH, Su Y, Wen Z, Yoritomo N, Ross CA, Margolis RL et al. Integration-free induced pluripotent stem cells derived from schizophrenia patients with a DISC1 mutation. Mol Psychiatry 2011; 16: 358-360.

69 Kessler RM, Woodward ND, Riccardi P, Li R, Ansari MS, Anderson S et al. Dopamine D2 receptor levels in striatum, thalamus, substantia nigra, limbic regions, and cortex in schizophrenic subjects. Biol Psychiatry 2009; 65: 1024-1031.

70 Markota M, Sin J, Pantazopoulos H, Jonilionis R, Berretta S. Reduced dopamine transporter expression in the amygdala of subjects diagnosed with schizophrenia. Schizophr Bull 2014; 40: 984-991.

71 Patel NH, Vyas NS, Puri BK, Nijran KS, Al-Nahhas A. Positron emission tomography in schizophrenia: a new perspective. J Nucl Med 2010; 51: 511-520.

72 da Silva Alves F, Figee M, van Amelsvoort T, Veltman D, de Haan L. The revised dopamine hypothesis of schizophrenia: evidence from pharmacological MRI studies with atypical antipsychotic medication. Psychopharmacol Bull 2008; 41: 121-132.

73 Grace AA. Dopamine system dysregulation by the hippocampus: implications for the pathophysiology and treatment of schizophrenia. Neuropharmacology 2012; 62: $1342-1348$

74 Kriks S, Shim JW, Piao J, Ganat YM, Wakeman DR, Xie Z et al. Dopamine neurons derived from human ES cells efficiently engraft in animal models of Parkinson's disease. Nature 2011; 480: 547-551.

75 Hartley BJ, Tran N, Ladran I, Reggio K, Brennand KJ. Dopaminergic differentiation of schizophrenia hiPSCs. Mol Psychiatry 2015; 20: 549-550.

76 Robicsek O, Karry R, Petit I, Salman-Kesner N, Muller FJ, Klein E et al. Abnormal neuronal differentiation and mitochondrial dysfunction in hair follicle-derived induced pluripotent stem cells of schizophrenia patients. Mol Psychiatry 2013; 18: 1067-1076.

77 Lodge DJ, Grace AA. Aberrant hippocampal activity underlies the dopamine dysregulation in an animal model of schizophrenia. J Neurosci 2007; 27: 11424-11430.

78 Perez SM, Shah A, Asher A, Lodge DJ. Hippocampal deep brain stimulation reverses physiological and behavioural deficits in a rodent model of schizophrenia. Int J Neuropsychopharmacol 2013; 16: 1331-1339.

79 Lodge DJ, Behrens MM, Grace AA. A loss of parvalbumin-containing interneurons is associated with diminished oscillatory activity in an animal model of schizophrenia. J Neurosci 2009; 29: 2344-2354.

80 Gilani Al, Chohan MO, Inan M, Schobel SA, Chaudhury NH, Paskewitz S et al. Interneuron precursor transplants in adult hippocampus reverse psychosisrelevant features in a mouse model of hippocampal disinhibition. Proc Natl Acad Sci USA 2014; 111: 7450-7455.

81 Lewis DA, Gonzalez-Burgos G. Pathophysiologically based treatment interventions in schizophrenia. Nat Med 2006; 12: 1016-1022.

82 Fung SJ, Webster MJ, Sivagnanasundaram S, Duncan C, Elashoff M, Weickert CS. Expression of interneuron markers in the dorsolateral prefrontal cortex of the developing human and in schizophrenia. Am J Psychiatry 2010; 167: 1479-1488.

83 Donegan JJ, Tyson JA, Branch SY, Beckstead MJ, Anderson SA, Lodge DJ. Stem cell-derived interneuron transplants as a treatment for schizophrenia: preclinical validation in a rodent model. Mol Psychiatry 2016; e-pub ahead of print 2 August 2016. doi: $10.1038 / \mathrm{mp} .2016 .121$.

84 Nicholas CR, Chen J, Tang Y, Southwell DG, Chalmers N, Vogt D et al. Functional maturation of hPSC-derived forebrain interneurons requires an extended timeline and mimics human neural development. Cell Stem Cell 2013; 12: 573-586.

85 Liu Y, Liu H, Sauvey C, Yao L, Zarnowska ED, Zhang SC. Directed differentiation of forebrain GABA interneurons from human pluripotent stem cells. Nat Protoc 2013; 8: 1670-1679. 
86 Maroof AM, Keros S, Tyson JA, Ying SW, Ganat YM, Merkle FT et al. Directed differentiation and functional maturation of cortical interneurons from human embryonic stem cells. Cell Stem Cell 2013; 12: 559-572.

87 Shetty AK, Bates A. Potential of GABA-ergic cell therapy for schizophrenia, neuropathic pain, and Alzheimers and Parkinsons diseases. Brain Res 2016; 1638: 74-87.

88 Braz JM, Sharif-Naeini R, Vogt D, Kriegstein A, Alvarez-Buylla A, Rubenstein JL et al. Forebrain GABAergic neuron precursors integrate into adult spinal cord and reduce injury-induced neuropathic pain. Neuron 2012; 74: 663-675.

89 Brennand KJ, Marchetto MC, Benvenisty N, Brustle O, Ebert A, Izpisua Belmonte JC et al. Creating patient-specific neural cells for the in vitro study of brain disorders. Stem Cell Reports 2015; 5: 933-945.

90 Nashun B, Hill PW, Hajkova P. Reprogramming of cell fate: epigenetic memory and the erasure of memories past. EMBO J 2015; 34: 1296-1308.

91 Hajkova P. Epigenetic reprogramming-taking a lesson from the embryo. Curr Opin Cell Biol 2010; 22: 342-350.

92 Polo JM, Liu S, Figueroa ME, Kulalert W, Eminli S, Tan KY et al. Cell type of origin influences the molecular and functional properties of mouse induced pluripotent stem cells. Nat Biotechnol 2010; 28: 848-855.

93 Yang N, Ng YiH, Pang Zhiping P, Südhof Thomas C, Wernig M. Induced neuronal cells: how to make and define a neuron. Cell Stem Cell 9: 517-525.

94 Ivanov NA, Tao R, Chenoweth JG, Brandtjen A, Mighdoll MI, Genova JD et al. Strong components of epigenetic memory in cultured human fibroblasts related to site of origin and donor age. PLoS Genet 2016; 12: e1005819.

95 Yehuda R, Daskalakis NP, Bierer LM, Bader HN, Klengel T, Holsboer F et al. Holocaust exposure induced intergenerational effects on FKBP5 methylation. Biol Psychiatry 2015; 80: 372-380.

96 Dietz DM, Laplant Q, Watts EL, Hodes GE, Russo SJ, Feng J et al. Paternal transmission of stress-induced pathologies. Biol Psychiatry 2011; 70: 408-414.

97 Vera $E$, Studer L. When rejuvenation is a problem: challenges of modeling lateonset neurodegenerative disease. Development 2015; 142: 3085-3089.

98 Studer L, Vera E, Cornacchia D. Programming and reprogramming cellular age in the era of induced pluripotency. Cell stem cell 2015; 16: 591-600.

99 Hussein SM, Batada NN, Vuoristo S, Ching RW, Autio R, Narva E et al. Copy number variation and selection during reprogramming to pluripotency. Nature 2011; 471: 58-62.

100 Vierbuchen T, Wernig M. Molecular roadblocks for cellular reprogramming. Mol Cell 2012; 47: 827-838.

101 Ho SM, Hartley BJ, Tcw J, Beaumont M, Stafford K, Slesinger PA et al. Rapid Ngn2induction of excitatory neurons from hiPSC-derived neural progenitor cells. Methods 2016; 101: 113-124.

102 Steinbeck JA, Jaiswal MK, Calder EL, Kishinevsky S, Weishaupt A, Toyka KV et al. Functional connectivity under optogenetic control allows modeling of human neuromuscular disease. Cell Stem Cell 2016; 18: 134-143.
103 Lancaster MA, Renner M, Martin CA, Wenzel D, Bicknell LS, Hurles ME et al. Cerebral organoids model human brain development and microcephaly. Nature 2013; 501: 373-379.

104 Pasca AM, Sloan SA, Clarke LE, Tian Y, Makinson CD, Huber N et al. Functional cortical neurons and astrocytes from human pluripotent stem cells in $3 \mathrm{D}$ culture. Nat Methods 2015; 12: 671-678.

105 Pozsgay V, Brisson JR, Jennings HJ. Synthesis of a tri- and a tetra-saccharide fragment of the capsular polysaccharide of type III group B Streptococcus. Carbohydr Res 1990; 205: 133-146.

106 Byers B, Lee HJ, Liu J, Weitz AJ, Lin P, Zhang P et al. Direct in vivo assessment of human stem cell graft-host neural circuits. Neuroimage 2015; 114: 328-337.

107 Hemmer K, Zhang M, van Wullen T, Sakalem M, Tapia N, Baumuratov A et al. Induced neural stem cells achieve long-term survival and functional integration in the adult mouse brain. Stem Cell Reports 2014; 3: 423-431.

108 Muotri AR, Nakashima K, Toni N, Sandler VM, Gage FH. Development of functional human embryonic stem cell-derived neurons in mouse brain. Proc Natl Acad Sci USA 2005; 102: 18644-18648.

109 Pedrosa E, Sandler V, Shah A, Carroll R, Chang C, Rockowitz S et al. Development of patient-specific neurons in schizophrenia using induced pluripotent stem cells. J Neurogenet 2011; 25: 88-103.

110 Hook V, Brennand Kristen J, Kim Y, Toneff T, Funkelstein L, Lee Kelly C et al. Human iPSC neurons display activity-dependent neurotransmitter secretion: aberrant catecholamine levels in schizophrenia neurons. Stem Cell Reports 3: 531-538.

111 Siegert S, Seo J, Kwon EJ, Rudenko A, Cho S, Wang W et al. The schizophrenia risk gene product miR-137 alters presynaptic plasticity. Nat Neurosci 2015; 18: 1008-1016.

112 Srikanth P, Han K, Callahan DG, Makovkina E, Muratore CR, Lalli MA et al. Genomic DISC1 disruption in hiPSCs alters Wnt signaling and neural cell fate. Cell Rep 2015; 12: 1414-1429.

113 Bavamian S, Mellios N, Lalonde J, Fass DM, Wang J, Sheridan SD et al. Dysregulation of miR-34a links neuronal development to genetic risk factors for bipolar disorder. Mol Psychiatry 2015; 20: 573-584.

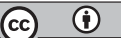

This work is licensed under a Creative Commons Attribution 4.0 International License. The images or other third party material in this article are included in the article's Creative Commons license, unless indicated otherwise in the credit line; if the material is not included under the Creative Commons license, users will need to obtain permission from the license holder to reproduce the material. To view a copy of this license, visit http://creativecommons.org/licenses/ by/4.0/

(c) The Author(s) 2017 